\title{
Intraorbital aneurysm of the ophthalmic artery
}

\author{
LOUIS MEYERSON AND S. J. LAZAR \\ Johannesburg, South Africa
}

Intraorbital aneurysm of the ophthalmic artery is a very rare condition. Duke-Elder (1952) mentioned seven reports, some of which lack anatomical verification; these were written between 1823 and 1914 when angiographic studies were not available and the verifications when done were post mortem studies.

Dempsey (1886) reported a saccular aneurysm of the ophthalmic artery at the back of the globe associated with a fusiform aneurysm of the internal carotid artery. The patient died and these aneurysms were found post mortem.

Wheeler and Baker (1964) found three aneurysms of the ophthalmic artery in 57 cases in which angiography was performed for ocular pathological studies. Only one of these was intraorbital.

Di Chiro ( $196 \mathrm{r}$ ) stated that aneurysms of the ophthalmic artery were rarely seen. Lombardi ( 1967 ), in 370 intracranial aneurysms seen before 1964 , found none in the ophthalmic artery. Parkinson, Jain, and Blair-Johnson (I96I) were unable to trace previous reports of saccular aneurysms arising from the ophthalmic artery.

\section{Case report}

A 55-year-old white man was first seen in 1963 , when the external examination of his eyes and ophthalmic investigations were negative apart from presbyopia.

PREVIOUS MEDICAL HISTORY

He had had an injury to the head during the second world war with uneventful recovery. At times he heard "blowing" noises in the head.

\section{FAMILY HISTORY}

A brother had died from a ruptured intracranial aneurysm, and the patient's only child had died at birth with a suspected intracranial haemorrhage.

\section{RECENT MEDICAL HISTORY}

On November 14, 1968, at 8 a.m. the patient coughed and developed a "haemorrhage and protrusion" of the right eye. An intramuscular injection of pethidine $50 \mathrm{mg}$. was given by his general practitioner, and he was examined (by L. M.) at I I a.m. on the same morning.

There was marked proptosis, a large subconjunctival haemorrhage, and a haemorrhage that had suffused into the lids and periorbital tissues (Figs I and 2, overleaf). The pupil was fixed and dilated and in the mid-position. There was no perception of light.

Received for publication September 3, 1970 

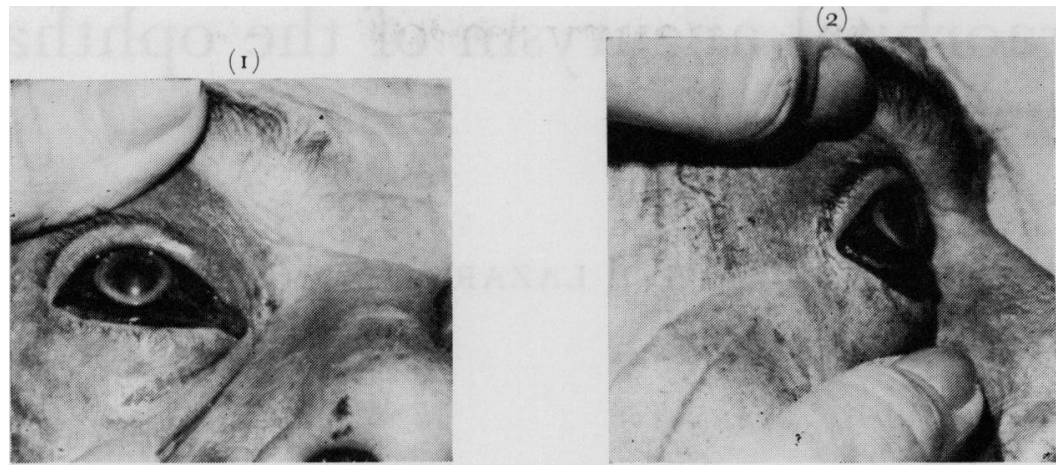

FIGS I and 2 Pre-operative appearance, showing proptosis, a large subconjunctival heamorrhage, and haemorrhage that has suffused into lids and periorbital tissues

The patient was admitted to the Brenthurst Clinic and treated with compress bandage and sedatives.

On the same evening the external features remained the same, corneal sensation was lost, and muscle movements were completely absent because of mechanical limitation of the globe. No bruit was heard.

The fundus showed marked dilatation of the larger and smaller retinal veins. There was little change at the macular area.

General physical and neurological examinations were performed by a physician and neurologist on the same day, but there were no significant findings.

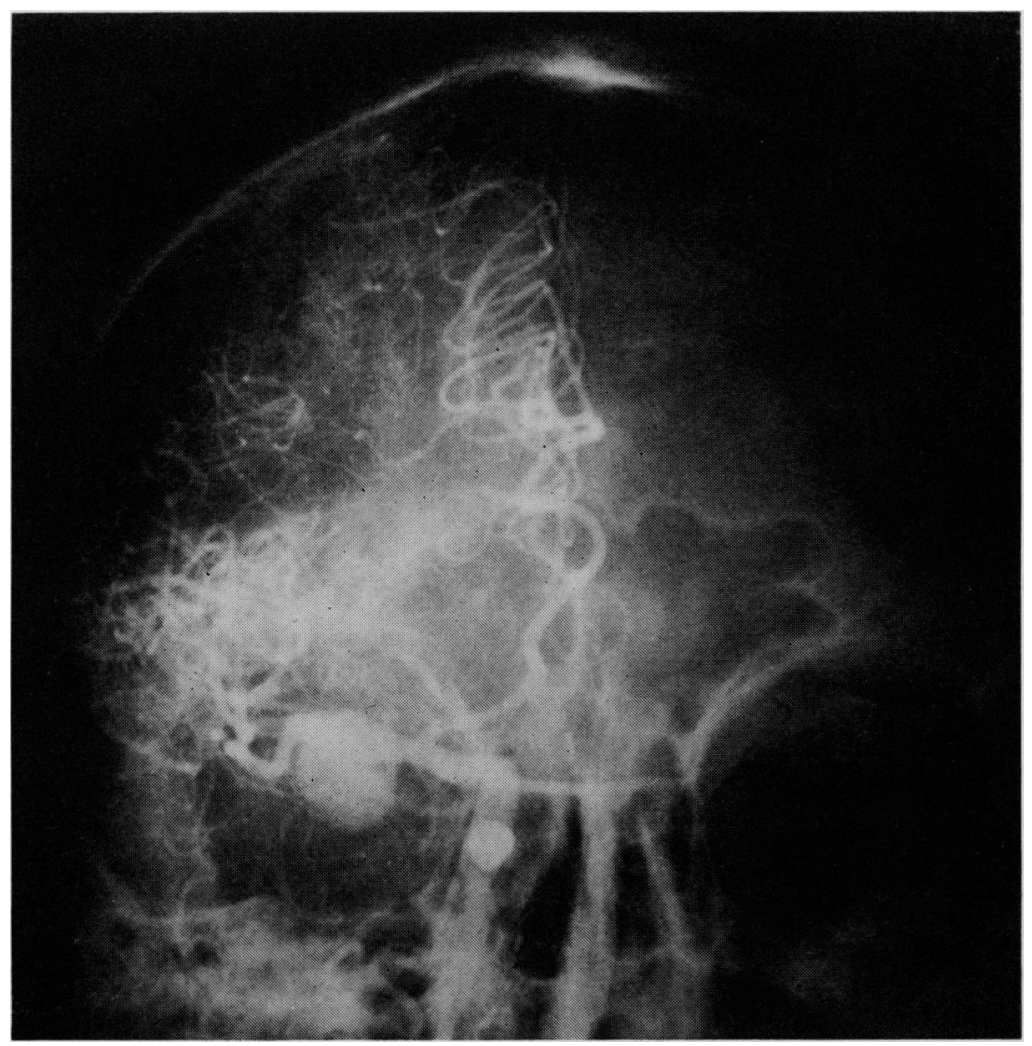

FIG. 3 Right

carotid antero-posterior angiogram, showing intraorbital aneurysm 
Blood studies (November I5, 1968). Packed cell volume: 44 vol. per cent., Erythrocyte sedimentation rate: $13 \mathrm{~mm}$./ $1 \mathrm{st} \mathrm{hr}$. (Wintrobe) (corrected rate $10 \mathrm{~mm}$./ $1 \mathrm{st} \mathrm{hr}$.). Non-fasting blood sugar: I05. Wassermann reaction: negative Blood count: normal.

\section{Radiology}

$X$ ray of the skull, including tomography of the orbits, revealed soft-tissue veiling over the right orbit but no evidence of bone destruction or calcification within the orbit. The optic foramina appeared normal on both sides. Bilateral carotid angiography under local anaesthesia on November I6, revealed a $1 \cdot 3 \mathrm{~cm}$. retro-ocular aneurysm in the right orbit. An irregular filling defect at the antero-inferior margin of the aneurysm probably represented blood clot. The ophthalmic artery was occluded close to the aneurysm. No other intracranial aneurysms were evident (Figs 3, 4, and 5).

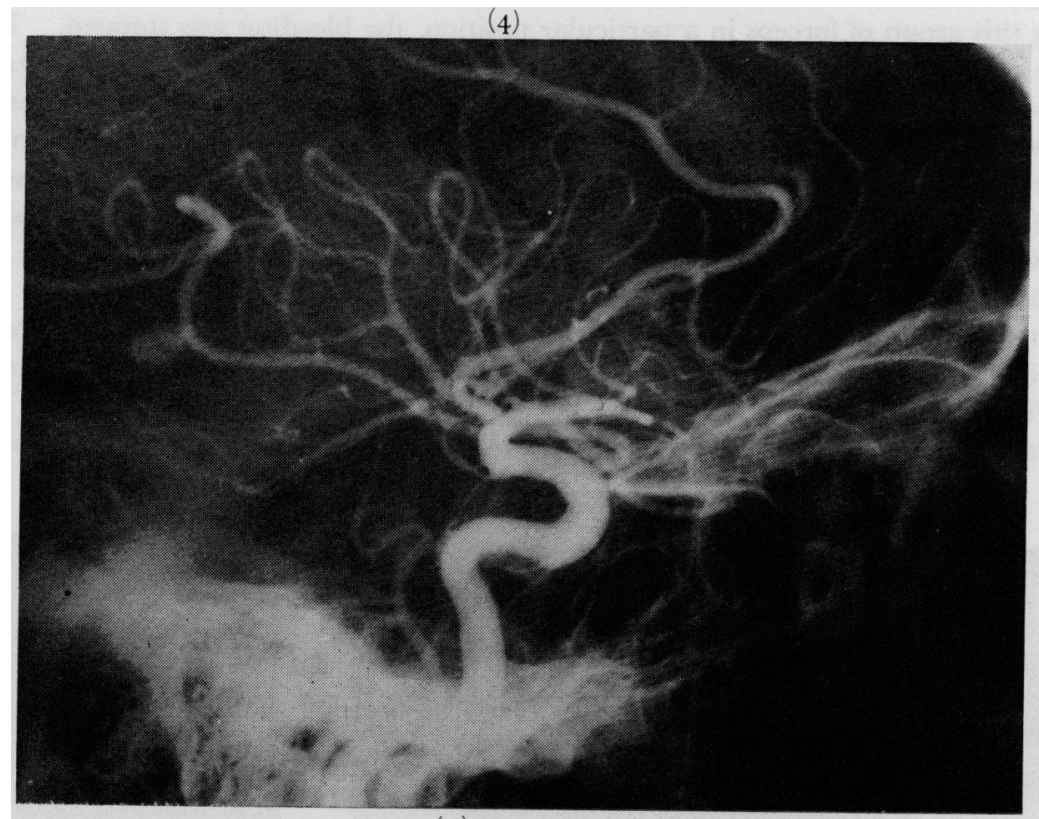

(5)

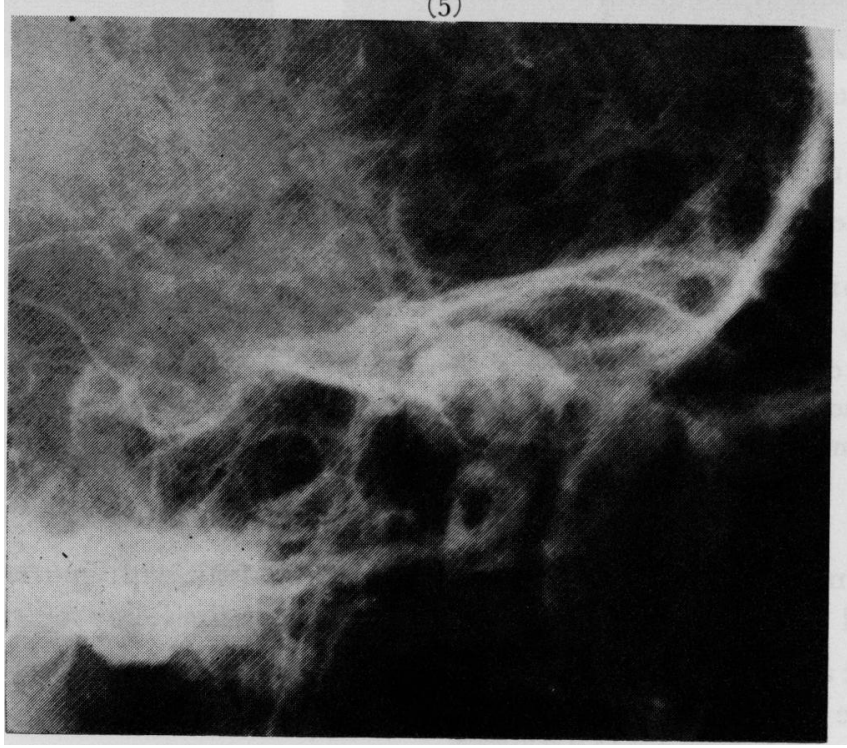

FIGS 4 and 5 Right lateral carotid angiograms, showing the aneurysm in arterial and venous phases.

Filling defects antero-inferiorly represent blood clot. The ophthalmic artery is demonstrated and a beaded appearance is noted. The artery tapers close to the aneurysm 


\section{DIAGNOSIS}

Blood leaking from an intraorbital aneurysm of the ophthalmic artery.

\section{MANAGEMENT}

On November 21, a right lateral orbitotomy was performed by Berke's approach. The laternal rectus was reflected and a necrotic black mass was seen to extend between the apex of the orbit and the globe.

An unsuccessful attempt was made to clip the anterior part of the mass, and further blunt dissection with sponges caused a massive haemorrhage, which could not be controlled by manual pressure through towels.

About six haemostats (artery forceps) were then applied to the mass at the apex of the orbit, and by keeping this group of forceps in a particular position, the bleeding was stopped. These forceps were taken off one at a time and it was then realized that the bleeding was being controlled by the pressure exerted by the tip of one forceps at the apex of the orbit. This pressure was maintained and the remnant of the black necrotic mass was dissected away. When the mass had been removed and the pressure of the haemostat at the apex of the orbit (optic foramen) was released there was no further bleeding. The laternal rectus muscle was resutured into position, the lateral part of the orbit was wired into position, and the wound was closed.

A transfusion of 2 pints of blood was given during the operation.

The postoperative period was uneventful. Muscle movements were full in all directions, except for dextroversion in which movement was absent. There was no ptosis and the proptosis resolved within a week (Figs 6 and 7 ).

Immediately after the operation the fundus showed a pale disc and a cherry-red spot at the macula.

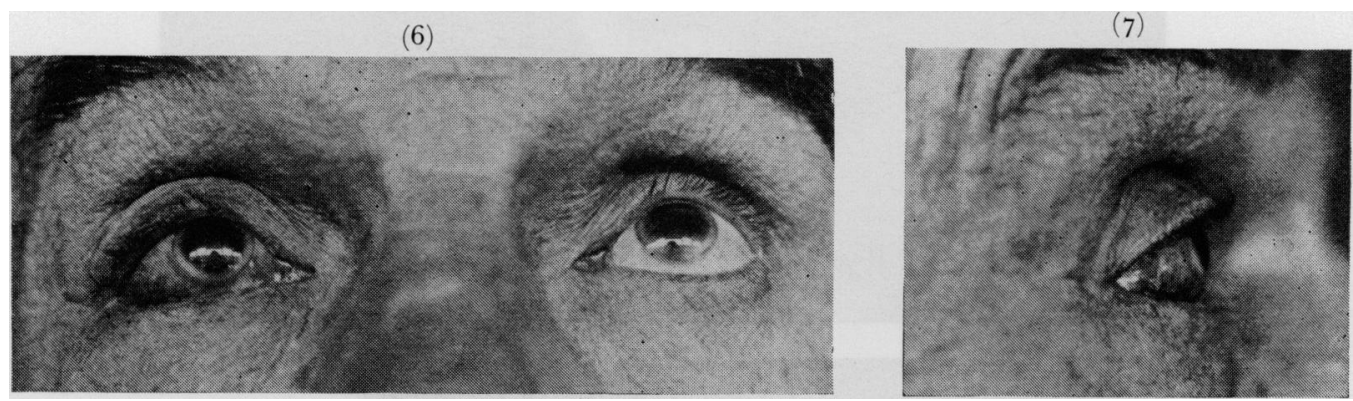

FIGS 6 and 7 Postoperative appearance, showing resolution of proptosis

PATHOLOGICAL FINDINGS

No arterial tissue was demonstrated.

POSTOPERATIVE RADIOLOGICAL FINDINGS

A cerebral angiography on January 10, 1969, under general anaesthesia showed successful obliteration of the aneurysm demonstrated previously. A metallic clip was noted at the site, and two metallic sutures were noted in the lateral wall of the orbit, the fragments of which were in good position. The ophthalmic artery was obliterated in the orbit (Figs 8 and 9).

\section{Comment}

A decision had to be made whether this aneurysm should be dealt with by the transfrontal approach or a lateral orbitotomy. The latter was chosen for the following reasons:

(a) The ophthalmic artery enters the orbit below the optic nerve and is rarely located on the medial side of the orbit. 


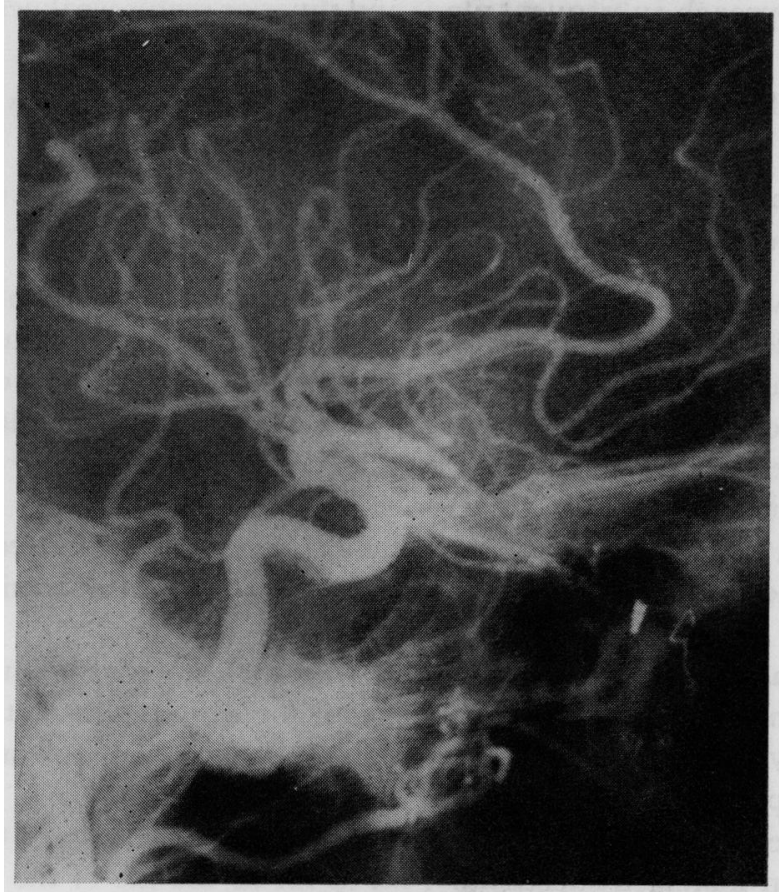

FIGS 8 and 9 Postoperative cerebral angiograms, showing successful obliteration of the intraorbital aneurysm of the ophthalmic artery

(9)

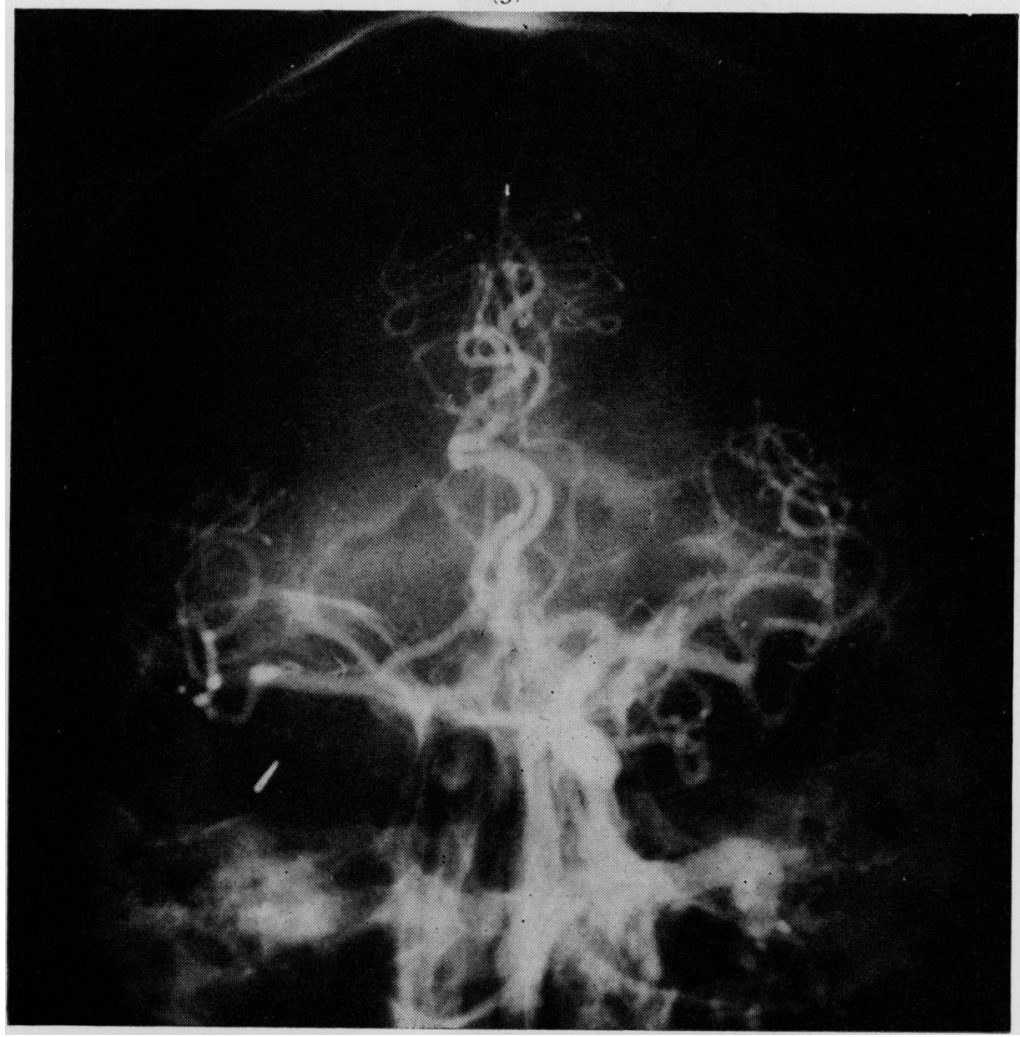


(b) In the transfrontal approach, subsequent ptosis and superior rectus weakness can occur. Mortality is high (4.1 per cent.) even in good hands (Stallard, I964).

(c) Excision of the frontal lobe has sometimes been necessary for better access to the orbitㅡㅡㅁ (Stallard, i964).

(d) Opening of the frontal and ethmoidal sinuses may lead to meningitis and rhinorrhoeao and a stormy postoperative period (Stallard, ig64).

The reason for the massive haemorrhage which occurred during the operation was thought to be the lack of elastic tissue in the wall of the aneurysmal remnant. Thus, when theo wall had been disrupted, no contraction took place and the short normal part of the artery had no stimulus to contract and continued to pump blood into the aneurysmal sac.

Had an enucleation been decided upon this complication would still have occurred.

Injury by the haemostats caused the VIth nerve palsy.

The absence of arterial wall tissue in the pathological specimen submitted to section may have been due to the disruptive nature of the preoperative and operative haemorrhages.

Radiologically there was no doubt that this was a ruptured saccular aneurysm of the $e^{\circlearrowright}$ intraorbital part of the ophthalmic artery and vascular malformations were not considered.

A comprehensive survey of the literature revealed a surprising paucity of cases of intraorbital aneurysm of the ophthalmic artery.

We believe this to be the first case of an aneurysm of the intraorbital part of the ophthal- $\frac{\rho}{-}$ mic artery which has been managed successfully, i.e. as far as the life of the patient wase concerned and also the preservation of the eye albeit blind.

\section{Summary}

A case of a patient who survived the rupture of an intraorbital aneurysm of the ophthalmic artery is presented. The management and radiological features are discussed.

\section{References}

DEMPSEY, A. (1886) Brit. med. F., 2, 54I

DI CHIRO, G. (196I) Radiology, 77, 948

DUKE-ELDER, s. (1952) "Textbook of Ophthalmology", vol. 5, p. 5405. Kimpton, London LOMBARDI, G. (1967) "Radiology in Neuro-Ophthalmology". Williams and Wilkins, Baltimore PARkinson, D., JAin, K. K., and Blair-Johnston, J. (ig6i) Canad. J. Surg., 4, 229

STAllaRd, H. B. (1964) In "Ocular and Adnexal Tumors", ed. M. Boniuk, p. 497. Mosby,

St. Louis

WHEELER, E. C., and BAKER, H. L. (1964) Radiology, 83, 26 